In the past there have been some uncertainties as to the status of the relations between the European High Pressure Research Group (EHPRG) and the Condensed Matter Division (CMD) of the European Physical Society (cf. Europhysics News, Vol. 4, No. 2, p. 1, February 1973). The undersigned wish to elucidate the situation.

The European High Pressure Research Group is in existence since 12 years. Its main activity is to organize one scientific conference every year.

After the Condensed Matter Division of EPS had been founded an affiliation of EHPRG to CMD was thought to be profitable. EHPRG would take care of scientific conferences in its field and thus would work like a section of CMD. Moreover, it was hoped that EHPRG may become an affiliated section of CMD. Because of the strict rules of EPS it was found impossible, however, to keep EHPRG as an affiliated (or associated) section in CMD, many members of EHPRG not being individual members of EPS.

The relations are now fixed on the following basis:

Both organizations, CMD and EHPRG, have different aims and different rules. They feel that they should keep a friendly relationship based on their common interests in furthering science by organizing scientific conferences of high standards.

To keep close relations the groups decided to invite representatives to every meeting of their respective board or committee and to supply all documents to that representative, the representative having no power to vote. The EHPRG representative to the board of CMD will be an indivividual member of EPS.

About 80 members of CMD have indicated their interest in the activities of a High Pressure Section of CMD. As there will not be a special High Pressure Section these members will find notice of future meetings of EHPRG in the Meetings Calendar of Europhysics News. They will receive individual information upon registration as a member of EHPRG. At present the membership fee is $£ 1.00$ per year.

For the European High Pressure Research Group:

K.-F. Seifert, Chairman, Mineralogisch-Petrologisches Institut der Universität Bonn, Poppelsdorfer Schloss, D-53 Bonn, Fed. Rep. Germany.

For the European Physical Society: H.B.G. Casimir, President,

A. Guinier, Chairman CMD.

\title{
European High Pressure Research Group
}

\section{J. Lees, Harlow, UK T. Evans, Reading, UK}

The early nineteen-sixties saw a very considerable expansion both in the amount and in the range of high pressure research work being conducted in the European Area. This expansion was to be seen in Government, in University and Technical College, and in Industrial Laboratories. It was realised early that, in this difficult technological field, much was to be gained by bringing together scientists and engineers with different interests, to discuss the common problems of high pressure research. High pressure research, then as now, was an area where the traditional subject boundaries of science and engineering, had become rather blurred.

The foundation of our Research Group was laid in 1963 on an initiative taken by Standard Telecommunication Laboratories Ltd., in bringing together scientists and engineers of widely differing backgrounds for an informal meeting on the problems and discoveries of high pressure research. The success and enthusiasm of this first meeting led to the formation of a broadly-based interdisciplinary society, to organize two- and three-day research conferences, usually once per year, and moving around various centres of European High Pressure Research. From the beginning the emphasis in our organisation and our conferences has been on informality. No record is published of the proceedings (none is made), and we aim to have as much discussion as possible both in the sessions themselves and in informal 'get-togethers' of scientists during the course of the conferences. In accordance with our ideal of multidisciplinary approach, anyone can put forward a contribution for discussion on any subject in high pressures at any of our conferences. In the interest of maintaining some time for discussions however (and of 'fitting-in' with the programmes of other high pressure conferences) we usually announce a general theme for any particular meeting, which is related to the scientific activities of the local organizers.

It was originally believed that, as high pressure techniques became better understood, the need for organisations such as EHPRG would disappear. Our experience has been quite the reverse - enthusiasm today is higher than ever, and our membership, stands at the record level of more than 300. Our members are drawn from twelve European countries and represent a wide spectrum of research interests, covering all aspects of materials behaviour at high pressures. While the main activity of EHPRG is the organisation of its annual research conference, it also aims to co-operate with national high pressure associations such as the High Pressure Technology Association (HPTA) in the UK and the Groupe Français des Hautes Pressions (GFHP) in France, and with the international bodies such as the Association Internationale pour l'Avancement de la Recherche et de la Technologie aux Hautes Pressions (AIRAPT) and with the European Physical Society (EPS).

\section{UNIVERSITY OF NEW SOUTH WALES}

\section{PROFESSOR}

\section{OF THEORETICAL PHYSICS}

Applications are invited for appointment to a new Chair of Theoretical Physics in the School of Physics. Other chairs are held by Professor E. P. George, the present Head of School, Professor H.J. Goldsmid and Professor K. N. R. Taylor.

The main interests of the School are in solid-state physics, magnetic materials, surface physics and biophysics. There is also substantial research activity in atomic physics and acoustics. The new professor will supervise and participate in teaching and examining undergraduate and postgraduate students in the School and engage in and promote research and advanced study in the field of his chair. He will be expected to provide leadership for a theoretical physics group and will be encouraged to collaborate with the experimental physicists.

Salary \$A 19,102 per annum. Subject to the consent of the University Council, Professors may undertake a limited amount of higher consultative work. The University reserves the right to fill any chair by invitation.

For details and conditions of appointment write to Appointments Office, P.O. Box 1, Kensington, N.S.W. 2033, Australia. Applications close 28th June, 1974. 